Casos Clínicos

Arch. Esp. Urol., 60, 9 (1.134-1.136), 2007

\section{QUISTE DE VESÍCULA SEMINAL CON AGENESIA RENAL ASOCIADO A MALFORMACIONES VASCULARES. PRESENTACIÓN DE UN CASO.}

\author{
Begoña Suárez Aliaga e Inmaculada Rodríguez \\ Jiménez.
}

Servicio de Radiodiagnóstico. MD Anderson. Madrid. España.

Resumen.- OBJETIVO: Presentamos un caso de malformación quística de vesícula seminal con agenesia renal ipsilateral asociada a alteraciones vasculares en aorta y cava, no descrito previamente en la literatura.

MÉTODOS Varón de 33 años de edad con historia de dolor abdominal y fiebre. Se realiza ecografía, urografía, TAC y RMN

RESULTADOS/CONCLUSIONES. La enfermedad quística de la vesícula seminal es poco frecuente. Se asocia a otras anomalías genitourinarias como la agenesia renal e incluso a alteraciones de la columna vertebral. Sin embargo, no se han descrito anomalías vasculares. El TAC es fundamental para determinar anomalías asociadas.

Palabras clave: Quiste vesícula seminal. Anomalías renales.

Begoña Suárez Aliaga

Játiva, 4 portal $H, 2^{\circ} B$

28007 Madrid. (España)

jcolmen@mixmail.com

Trabajo recibido: 9 de febrero 2007
Summary.- OBJECTIVE: We report a case of seminal vesicle cyst with ipsilateral renal agenesis associated wit abnormalities of the abdominal great vessels, not described previously in the bibliography.

METHODS: 33 year-old-male with history of abdominal pain and fever. This case was evaluated by ultrasound, IV urography, CT scan and MRI.

RESULTS/CONCLUSIONS. Congenital cystic disease of the seminal vesicle is an uncommon disorder. It is associated with genitourinary anomalies, often renal agenesis, and even anomalies of the lower spine. However, anomalies of the abdominal great vessels have not been described previously. CT scan provided excellent demonstration of associated anomalies.

Keywords: Seminal vesicle cyst. Renal anomalies.

\section{INTRODUCCIÓN}

La enfermedad quística de las vesículas seminales es una patología poco frecuente. Zinner describió la asociación de quistes de vesículas seminales con agenesia renal y otras anomalías genitales (1). Artículos recientes sugieren que la alteración del desarrollo del conducto mesonéfrico da lugar a quiste de vesícula seminal asociado a anomalías genitourinarias (2). Ha sido descrita asociación a anomalías en el desarrollo de la columna lumbar, como la hemivértebra (3). Sin embargo anomalías vasculares no se refieren en la literatura. Presentamos un caso de quiste de vesícula seminal con agenesia renal y malformaciones en aorta y cava abdominal y describimos las características de imagen.

\section{CASO CLÍNICO}

Paciente de 33 años que acude al Servicio de Urgencias por sintomatología de dolor abdominal y fiebre. Las pruebas analíticas son normales y la exploración clínica anodina. Se realiza ecografía abdominal donde se pone de manifiesto ausencia del riñón izquierdo con hipertrofia compensadora del derecho. En la exploración ultrasonográfica de la pelvis se observa asimetría entre ambas vesículas seminales presentando la izquierda un tamaño de 2.5 centímetros con aspecto globuloso (Figura 1). Posteriormente se realiza una urografía intravenosa donde se confirmó la ausencia de riñón izquierdo con un riñón derecho agrandado sin signos de dilatación del sistema excretor. La vejiga muestra un aspecto normal con inserción del ureter derecho correctamente abocado. Se completa la exploración con TAC abdominal para valoración de la imagen quística pélvica vista en la ecografía confirmándose un aumento de tamaño de la vesícula seminal del lado izquierdo con una imagen ovoidea adyacente con densidad de partes blandas con unas dimensiones en conjunto de $5.5 \times 4 \times 3$ centímetros (Figura 2). 


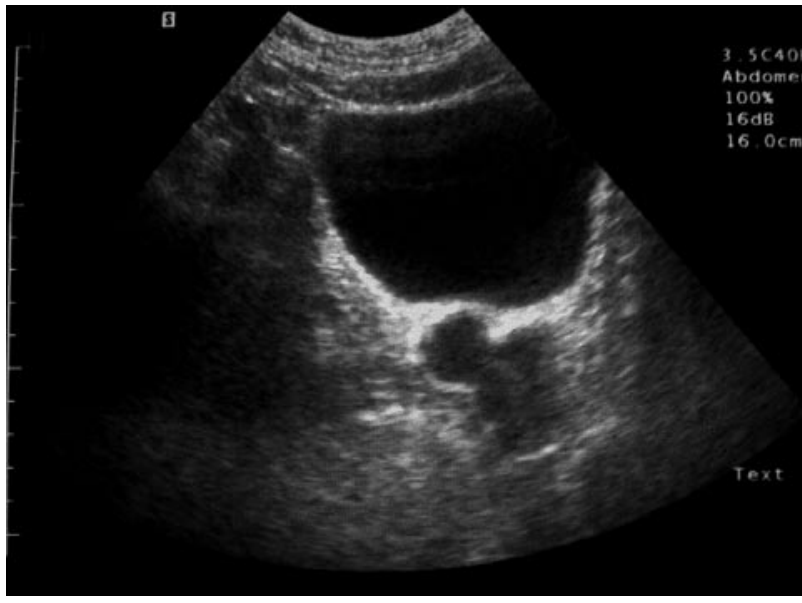

FIGURA 1. Ecografía pélvica donde se visualiza una masa globulosa en el lugar teórico de la vesícula seminal izquierda.

Se identifica una bifurcación aórtica alta, a nivel de LI, con una rama iliaca izquierda muy lateralizada y una iliaca derecha con una morfología y ubicación similar a la aorta. La cava presenta una bifurcación a igual nivel con una teórica iliaca izquierda que se lateraliza de igual manera que la arteria y una teórica iliaca derecha con morfología de vena cava que posteriormente se bifurca en dos vasos en el lugar normal de bifurcación de la cava, mostrando dichos vasos una asimetría en el tamaño, siendo mayor el derecho con una vena iliaca izquierda casi imperceptible (gráfico), (Figuras 3 y 4).

Se completa la exploración con RMN dada la alta densidad de la lesión pélvica la cual revela una masa quística polilobulada con imágenes tubuliformes que desembocan en la glándula prostática lo que confirma el diagnóstico de quiste de vesícula seminal (Figura 5).

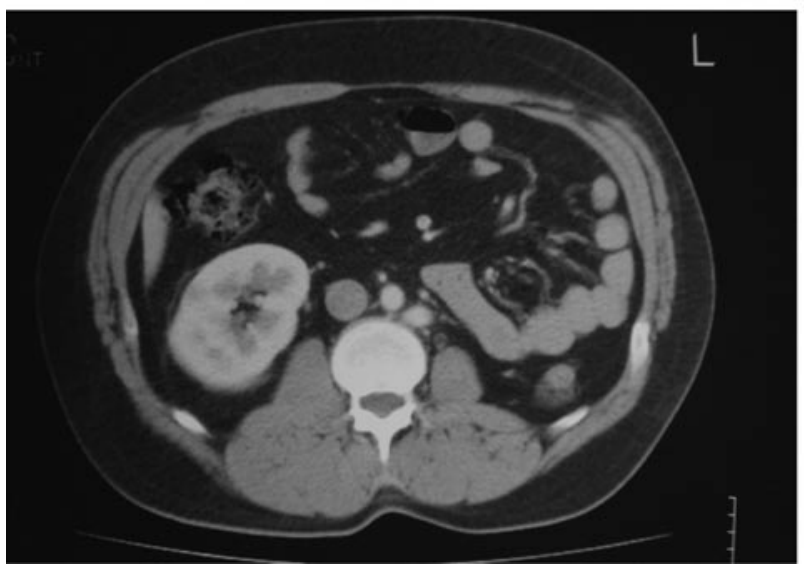

FIGURA 3. TAC abdominal donde se pone de manifiesto una bifurcación aórtica alta en el nivel del primer cuerpo vertebral lumbar.

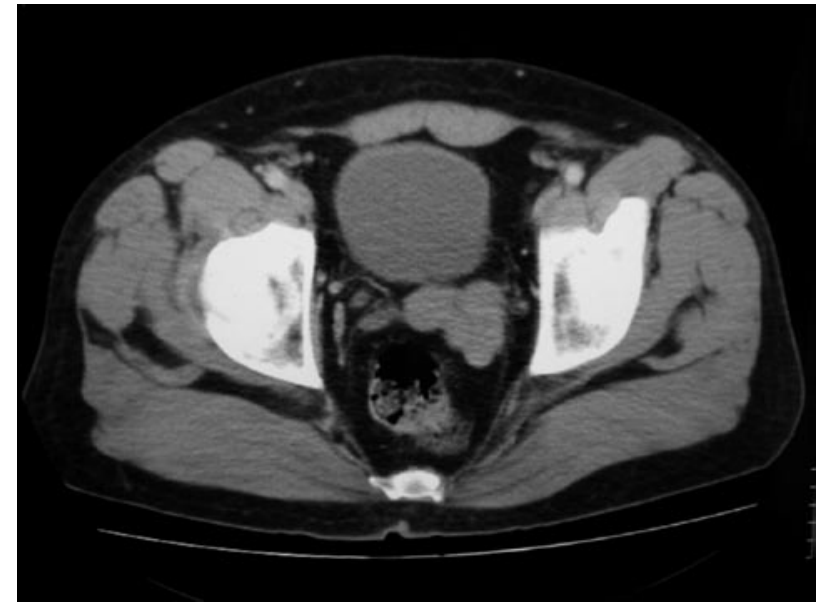

FIGURA 2. TAC a nivel de la pelvis donde se confirma la presencia de una lesión polilubulada que corresponde a la vesícula seminal.

\section{DISCUSIÓN}

La enfermedad quística de las vesículas seminales puede ser congénita $o$ adquirida (4). Los quistes de vesículas seminales congénitos se asocian a anomalías de las estructuras derivadas del conducto mesonéfrico ipsilateral, como los riñones $(5,6)$.

El $80 \%$ de pacientes con quistes de vesícula seminal presentan disgenesia renal ipsilateral y en un $8 \%$ duplicación del sistema colector. Otras anomalías asociadas del tracto urogenital son la ectopia ureteral, el cual termina en la vesícula seminal $(3,5)$.

El principal síntoma es el dolor, que puede ser abdominal, pélvico o perineal lo que puede ser provocado por el efecto masa. Otros síntomas son disuria, infección o

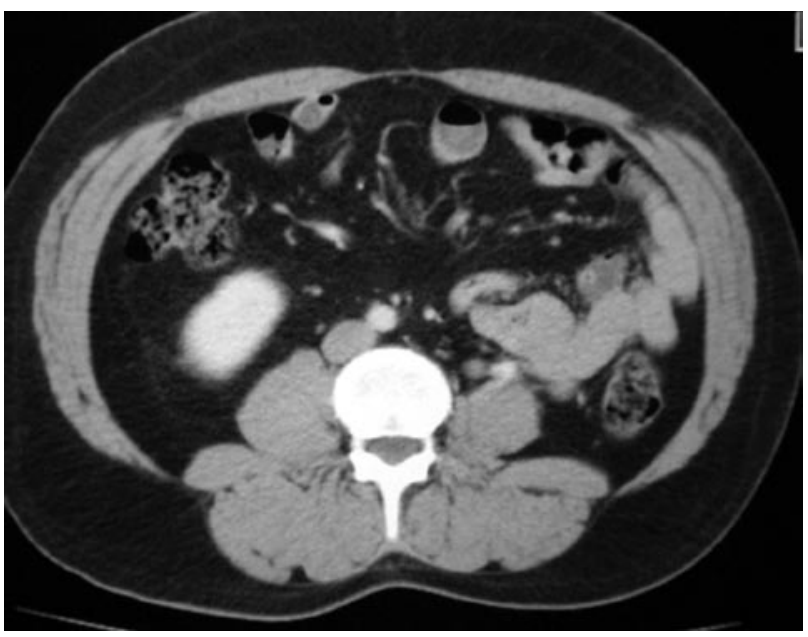

FIGURA 4. TAC abdominal. Bifurcación aortocava alta con lateralización izquierda de los vasos ilíacos del mismo lado. 


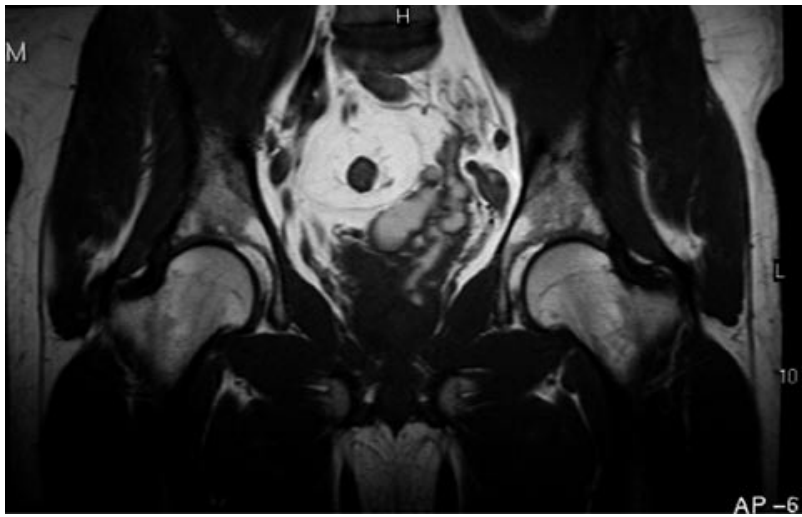

FIGURA 5. RMN. Se visualiza una masa quística polilobulada con imágenes tubuliformes que desembocam en la glándula prostática

urgencia miccional (5). En nuestro caso presentó dolor abdominal y fiebre. Las pruebas de imagen nos revelaron una masa quística a nivel de la vesícula seminal izquierda con agenesia renal asociada. Hay muchas causas de masas pélvicas en hombres. Los pequeños quistes pueden derivar de la próstata, conductos eyaculadotes o glándulas de Cowper. Los tumores pueden derivar de la vejiga, próstata, uretra u otras estructuras pélvicas como las vesículas seminales (2). Sin embargo, ninguno de estos procesos se asocia a agenesia renal.

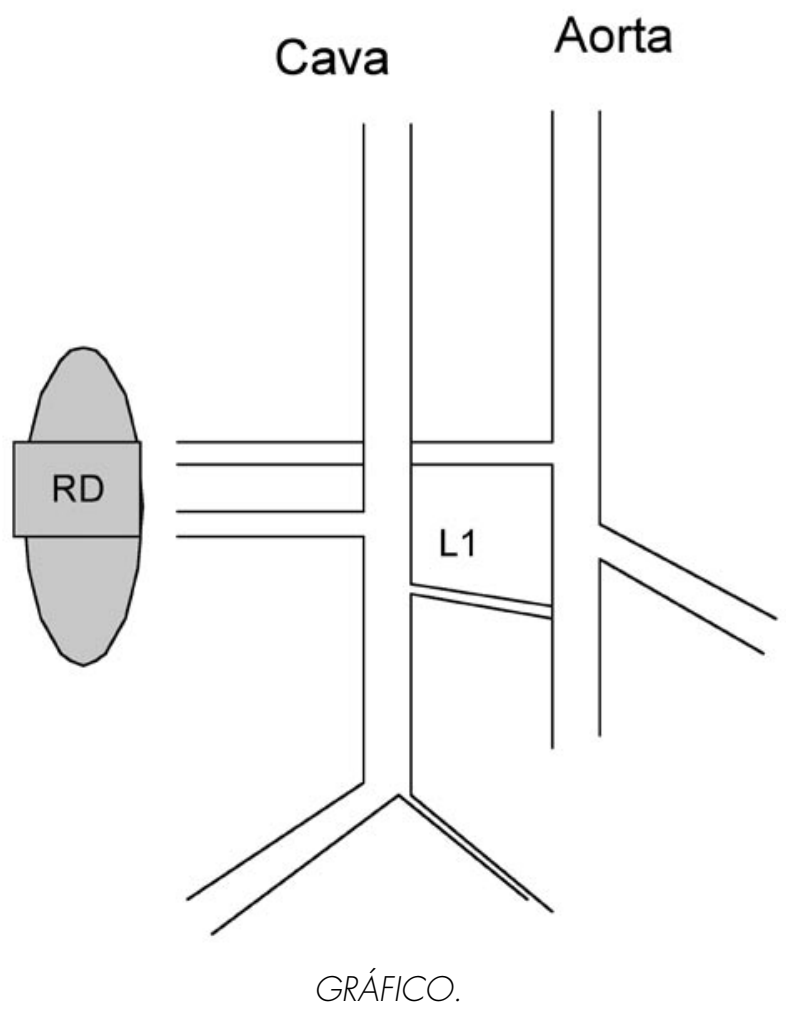

Incidentalmente descubrimos anomalías vasculares que afectaban a la cava y a la aorta abdominal, hallazgo no descrito con anterioridad en la literatura.

La ecografía como método diagnóstico inicial es bueno para descartar otras causas de dolor abdominal y demostrar la agenesia renal así como la imagen quística de la pelvis. La urografía confirma la ausencia renal pero en nuestro caso no revela alteraciones relacionadas con el quiste de vesícula seminal (impronta vesícal) probablemente por su pequeño tamaño. El TAC permite confirmar la ausencia de riñón así como excluir riñón rudimentario o ectópico y valorar otras anomalías asociadas como la hemovértebra o como es el caso de nuestro paciente donde se descubrieron alteraciones aorto-cavas. EL TAC, además, determina la existencia de la lesión pélvica con sus correlaciones anatómicas. La identificación de una vesícula seminal normal y otra ausente con un quiste ipsilateral de pared gruesa es definitiva (7). Sin embargo, en los quistes grandes la anatomía de la uretra y del suelo de la vejiga puede estar distorsionada y ser necesaria RMN (8).

La RMN permite determinar la exacta relación anatómica y dependencia de una masa pélvica, así como demostrar la naturaleza quística en las lesiones con contenido. Hacemos referencia a la necesidad de buscar anomalías vasculares, óseas o de otra naturaleza en este tipo de pacientes.

\section{BIBLIOGRAFÍA Y LECTURAS RECOMENDADAS (*lectura de interés $y^{* *}$ lectura fundamental)}

1. ZINDER, A.: "Ein fall von intravesikaler samenblasencyste". Wien Med. Wochenschr., 64: 605, 1914.

**2. KENNEY, P.J.; LEESON, M.D.: "Congenital anomalies of the seminal vesicles:spectrum of computed tomographic findings". Radiology, 149: 247, 1983.

*3. SHEIH, C.; LIAO, Y.; LI, Y. y cols.: "Seminal vesicle cyst associated with ipsilateral renal malformation and hemivertebra: report of 2 cases". J. Urology, 150: 1214, 1993.

4. WEYMAN, P.J.; McCLENNAN, B.L.: "Computed tomography and ultrasonography in the evaluation of mesonephric duct anomalies”. Urol. Radiol., 1: 29, 1979.

**5. BERNARD, F.K.; ROBERT, R.H.; MICHAEL, M.L. y cols.: "Congenital cystic disease of the seminal vesicle". Radiology, 178: 207, 1991.

6. HEANEY, J.A.; PFISTER, R.C.; MEARES, E.M.: "Giant cyst of the seminal vesicle with renal agenesis". AJR, 149: 139, 1987.

7. LANTZ, E.; BERQUIT, T.H.; HATTERY, R. y cols.: "Seminal vesical cyst associated with ipsilateral renal agenesis:a case report". Urol. Radiol., 2: 265, 1981.

8. KNEELAND, J.B.; AUH, Y.H.; McCARRON, J.P. y cols.: "Computed tomography, sonography, vesiculography and MR imaging of a seminal vesicle cyst". J. Comput. Assist. Tomogra., 9: 964, 1985. 